\title{
(Re)pensar os movimentos sociais
}

Olivier FILLIEULE, Éric AGRIKOLIANSKY e Isabelle SOMMIER (orgs.). Penser les mouvements sociaux: conflits sociaux et contestations dans les sociétés contemporaines. Paris, La Découverte, 2010. 327 páginas.

\section{Ernesto Seidl}

Se qualquer tentativa atual de balanço dos estudos sobre movimentos sociais identificaria uma bem estabelecida e dominante vertente anglo-saxã, em um polo, e outra mais jovem e vibrante vertente francesa, em outro, sem dúvida a questão mais interessante seria o vigor notável resultante do contato entre elas. Contato este promovido, sem surpresa, por uma sociologia dos movimentos sociais que desde o início dos anos de 1990 vem se constituindo como área bem demarcada na França, na encruzilhada entre ciência política, sociologia, antropologia e história. Após duas décadas de afirmação à base de uma alta produtividade e de esforços de renovação do horizonte de pesquisas, são os próprios especialistas do lado francês que propōem um balanço crítico (e algo mais). É o que o leitor encontrará ao longo dos treze artigos da coletânea Penser les mouvements sociaux: conflits sociaux et contestations dans les sociétés contemporaines.

A estratégia de demarcação proposta pelos autores é apresentada sem meias palavras em uma introdução esclarecedora. De início, o reconhecimento inegável do trabalho robusto de especialistas anglo-saxōes - Charles Tilly à frente de todos - que, a partir dos anos de 1970, construíram uma subdisciplina dotada de elevada unidade em termos teórico-metodológicos. Assim, pois, o modelo contentious politics teria forjado instrumentos imprescindíveis ao estudo dos ditos movimentos sociais, fixando vocabulário consagrado que inclui conceitos como estrutura de oportunidades, organizaçôes, recursos, repertórios de ação e ciclos de mobilização. Em seguida, a constatação de relativa estagnação daquele mesmo paradigma, com dificuldades em se reformar, oferece então o flanco a ser explorado pelos especialistas franceses - abertamente tributários da escola que julgam merecer oxigenação. 
Um indício da contribuição francesa a esta renovação do campo dos movimentos sociais estaria justamente na fragmentação das agendas de pesquisa, dos métodos, dos sistemas conceituais e de suas bases disciplinares. Isto é, o enfrentamento à tentação de comodidade do esoterismo da linguagem e dos conceitos, à rotinização das bibliografias, ao fechamento da disciplina. $\mathrm{O}$ resultado de tal tomada de posição poderia ser visto, segundo os autores, na diversidade e originalidade do que chamam de sociologia francesa dos movimentos sociais. Mais precisamente, os traços apresentados como originais por essa sociologia incluem o recurso aos instrumentos da sociologia crítica; a desconfiança diante das formas positivistas de administração da prova e de construção argumentativa; a renovação da sociologia da militância e do engajamento individual; o distanciamento de temas canônicos e o desenvolvimento de pesquisas em universos fora do Ocidente; a profusão de estudos sobre os movimentos chamados "sem" ("sem teto", "sem documentos"), mas também sobre os conflitos do trabalho e a ação sindical; os diálogos com pesquisas sobre grupos de interesse, a construção de problemas públicos e os usos protestatórios de canais institucionais de expressão, como o direito (p. 9).

Atenção especial é dada ao aspecto metodológico das abordagens francesas, as quais rechaçariam o "comparatismo estratosférico" em benefício da complexidade dos contextos específicos. Nesse ponto, a nosso ver, esboça-se clivagem de fundo entre as condições de exercício das ciências sociais na França e nos Estados Unidos. Do lado anglo-saxão (sobretudo norte-americano), uma indústria pesada de pesquisa, a afeição ao quantitativismo e a estudos longitudinais; do lado francês, a dimensão artesanal que conduz a privilegiar o qualitativo, os estudos em pequena escala que procuram ganho em profundidade. Aos olhos franceses, esta característica aparece como trunfo, dada uma suposta maior densidade explicativa de esquemas elaborados num corpo-a-corpo empírico intenso e minucioso. Entre as pistas exploradas por seus trabalhos, destacam-se algumas questões de análise: "a lógica das trajetórias militantes, as emoções e os afetos, os procedimentos de atribuição de sentido, individuais ou coletivos, a dinâmi- ca dos eventos e as interações do face a face que constituem a trama do protesto" (p. 10).

Para ilustrar essas oposições e a pretendida originalidade na análise dos movimentos sociais, recorre-se ao exemplo de pesquisas sobre o movimento dito altermundialista, objeto que tem merecido grande atenção de autores franceses (em especial Éric Agrikoliansky, Isabelle Sommier e Olivier Fillieule, organizadores da coletânea em questão) na última década. Assim, a recusa a um tratamento metodológico exclusivamente apoiado em surveys dá lugar a procedimentos que combinam a administração de questionários de caráter qualitativo, entrevistas e etnografias a uma "abordagem genealógica” voltada à compreensão das nuanças ideológicas do movimento e às transformações do espaço das organizações. Três ganhos principais poderiam ser elencados como resultado dessas apostas metodológicas. Em primeiro plano, a relativização tanto do caráter "novo" como da dimensão "transnacional” do movimento altermundialista. Ao examinar as lógicas organizacionais de investimento no "transnacional" e as longas carreiras militantes de dirigentes, as análises dariam conta de quanto a emergência do "movimento" deve a condições nacionais (na França) ligadas à recomposição do espaço dos movimentos sociais na era Mitterand (19811995). A apreensão desta "configuração histórica e nacional singular” permitiria compreender, desse modo, as questôes que conduzem

[...] uma organização, mas também atores particulares em seu interior, a se projetar no plano internacional e a se profissionalizar, ou a reescrever lutas locais na escala da 'batalha contra o neoliberalismo', como conseguiu fazer, por exemplo, um José Bové com o caso do embargo do roquefort, fornecendo assim ao 'movimento' algumas de suas páginas e datas fundadoras (p. 11).

A fim de se protegerem da crítica de franco-centrismo ou de generalização de um caso particular, os autores notam que as mesmas hipóteses foram testadas em outros países europeus. Dessas comparaçôes teria emergido um segundo ganho importante nas análises do fenômeno: o fim da 
crença na unidade do movimento altermundialista. $\mathrm{Ou}$, dito de outra forma, a constatação da variedade de pioneiros em cada país estudado (os "novos movimentos sociais" na Alemanha, as organizações de solidariedade internacional e os movimentos ambientalistas na Grã-Bretanha, os novos sindicatos na França e na Itália). Por fim, uma terceira e mais recente vantagem metodológica apresentada estaria ligada à abordagem das lógicas de importação e exportação do modelo "fórum", como realizado em pesquisas antes e durante o Fórum Social Mundial de Nairóbi, em 2007.

A estrutura da coletânea em dois blocos de sete e seis capítulos, respectivamente, obedece à lógica indicada logo nos primeiros parágrafos da introdução, qual seja, discutir soluções aos impasses do modelo contentious politics através da contribuição francesa. No primeiro bloco, os esforços concentram-se no questionamento sistemático à consistência do edifício conceitual anglo-saxão centrado nos conceitos de mobilização de recursos, estruturas de oportunidade, análise de discurso (frame analysis), repertórios de ação e ciclo de mobilização, com indicaçôes cuidadosas de sua história, usos e pontos fortes, mas sobretudo de seus limites e possibilidades de superação. No segundo bloco, ponto alto da obra, trata-se mais explicitamente de apontar procedimentos de análise dos movimentos sociais em geral negligenciados pelo modelo contentious ou então abordados de forma superficial (a dimensão afetiva dos movimentos, a questão da identidade coletiva, os usos do direito para o protesto, protesto e mídia).

O fato de realizar em espaço reduzido discussão clara e circunstanciada em torno dos aportes fundamentais da sociologia dos movimentos sociais de língua inglesa já garantiria bons méritos à empreitada do livro. Poderia servir aos interessados na temática, por exemplo, uma aproximação inicial econômica a seu estado da arte. Obviamente, o esforço notável dos autores em enfrentar de modo crítico vastíssima bibliografia a partir de experiências de pesquisa e com dados próprios em mãos oferece gama muito maior de interesse ao leitor. Destacaríamos alguns eixos que nos parecem mais instigantes a pesquisadores do universo dos movimentos sociais, da militância e da participação política.
Num nível mais geral, a principal linha de tensão entre as vertentes deriva de uma abordagem mais macrossociológica do modelo contentious politics, fortemente marcada pela importação de questôes da sociologia (e da teoria) das organizações e das ciências econômicas, em oposição a uma sociologia da ação social (individual e coletiva), muito ancorada na história e atenta a particularidades. A ênfase do modelo anglo-saxão em dimensões internas dos movimentos sociais, sobretudo via o par de noções organização e recursos, cristalizou formas de pensar o fenômeno da mobilização social em termos de sua dinâmica própria. Isto é, de como se dão, concretamente, processos de formação de movimentos quanto a condiçôes de surgimento de organizaçôes - no sentido de empresas inseridas em um mercado ou indústria (Social Movement Industries, SMI) - capazes de acumular recursos (dinheiro, estrutura física, quadros profissionais), recrutar adeptos, garantir audiência e, enfim, atingir os objetivos propostos. A esta perspectiva então inovadora, lançada por John McCarthy e Mayer Zald em 1977 e transformada em escola, Doug McAdam acrescentou, na trilha direta do mentor Charles Tilly, o conceito de estrutura de oportunidades politicas. Procurava-se assim dar algum espaço à história, aos contextos e às conjunturas em estudos que tentavam dar conta das lógicas de constituição de movimentos sociais sobretudo nos Estados Unidos, matizando em alguma medida a visão empresarial/logística/racional da escola da mobilização de recursos.

As críticas levantadas a esses aspectos pelos autores franceses, em especial Emmanuel Pierru, Lilian Mathieu e Olivier Fillieule, não chegam a apresentar surpresas. Insistem na esquematização excessiva do modelo mobilizing structures, em parte pela referência à realidade norte-americana de um espaço peculiarmente profissionalizado e institucionalizado dos movimentos que se expande desde os anos de 1960, com crescente número de agências especializadas na construção de "problemas sociais" e a proliferação de um setor "sem fins lucrativos" e de organizações sem base de militantes. Além disso, o modelo também pecaria por não dar atenção devida à diversidade de formas e repertórios organizacionais; vale dizer, tenderiam a perder de vista os 
diferentes tipos de organização (com liderança carismática, mais ou menos informal, dotada ou não de "nichos militantes" permanentes, por exemplo) e suas histórias/"trajetórias" particulares.

Por sua vez, as propostas de superação do uso consagrado do conceito de estrutura de oportunidades trazem maior novidade à ambição de se compreender a influência do contexto político na emergência e no desenvolvimento de mobilizações. Em linhas gerais, entraria em conta a questão complexa das relações entre espaço ou campo político (no sentido institucional, estatal-partidário) e movimentos sociais, aspecto que no esquema anglo-saxão garante o primado da política institucional em definir as condições (oportunidades, ofertas) para o florescimento de movimentos. A aposta na ideia de autonomia e interdependência entre os dois espaços sociais permitiria esclarecer tanto as diferenças nas formas de atuação como as questões em disputa no espaço dos partidos e nos movimentos, além de mostrar o que os diferencia e o que os une. Nessa ótica, o recurso a noções como campo, espaço ou arena dos movimentos sociais, desenvolvidas há alguns anos por estudiosos franceses, traria instrumental mais fino ao estudo de questôes candentes como, por exemplo, a multiposicionalidade militante e as lógicas de transferência entre atuaçôes (simultâneas ou sucessivas) de atores em partidos e outras esferas de mobilização (sindicatos, ONGs, cooperativas, associaçôes).

Por fim, em estreita conexão com esse aspecto, sublinhamos na obra as contribuiçôes de uma sociologia da militância que tem trazido novo fôlego às agendas de pesquisa sobre movimentos sociais e estimulado, inclusive, combinaçôes com abordagens de corte institucional no estilo contentious politics. Entre os questionamentos e objetos de maior vigor, como indicam sobretudo Olivier Fillieule e Bernard Pudal em seu capítulo, têm se mostrado ricas as análises voltadas às condiçôes (objetivas e subjetivas) de engajamento e de militância, bem como ao fenômeno do desengajamento ou defecção, à apreensão das diversas lógicas de retribuição e de percepção envolvidas no processo, entre outras. $\mathrm{O}$ peso da sociologia disposicional fica evidente em esquemas que buscam integrar propriedades sociais e disposições ligadas a processos de engajamento (interesse, valorização e, enfim, passagem ao ato de participação) com as configurações sociais que favorecem (ou não) - em intensidades variáveis - a realização de carreiras militantes. E é justamente a incorporação do instrumental interacionista de Chicago (Becker, Strauss, Gerth, Mills), realizada por pesquisadores franceses, que aparece como avanço nas abordagens da militância, em especial pelo uso da noção de carreira. Esta permitiria, segundo Fillieule e Pudal, trabalhar em conjunto as questôes "das predisposiçôes à militância, da passagem ao ato, das formas diferenciadas e variáveis no tempo adquiridas pelo engajamento, da multiplicidade dos engajamentos ao longo do ciclo de vida" e da "retração ou extensão dos engajamentos" (p. 172). Tal abordagem processual do fenômeno ofereceria ao analista meios de conjugar história individual, instituição e contextos, com atenção a dimensões tão importantes quanto posição social e socialização dos atores, suas inserçôes em diferentes esferas (religião, grupos culturais, profissão) e deslocamentos no espaço social, os contextos históricos e culturais que enquadram as biografias e as interações e jogos de poder tramados no interior das instituições/organizações. Em síntese, amplas perspectivas de estudo.

\section{ERNESTO SEIDL é professor do Departamento de Ciências Sociais da Universidade Federal de Sergipe - UFS. Email: <eseidl@terra.com.br>.}

